\title{
OBJECT ASSIGNMENT IN S.C. DIK'S FUNCTIONAL GRAMMAR: MARGINAL ACCESSIBILITY IN ENGLISH
}

\author{
PILAR GUERRERO MEDINA \\ Universidad de Córdoba
}

\begin{abstract}
The approach to Subject and Object assignment in Dik's Functional Grammar is one of the most controversial aspects of the theory. Dik (1997) formulates a universal hierarchy of semantic functions determining accessibility to the Subject and Object functions. The "cut-off point" for Object assignment in English is established after the Beneficiary. However, it is my contention that Object assignment is not restricted to Goal, Recipient and Beneficiary terms. As I will try to illustrate in this paper, there are other more marginal possibilities that suggest that the productivity of Object assigment is a matter of degree (cf. Brdar and Brdar Szabó 1993).
\end{abstract}

\section{RESUMEN}

La asignación de las funciones sintácticas Sujeto y Objeto es uno de los aspectos más problemáticos planteados en la Gramática Funcional de Dik (1997). En esta teoría las posibilidades de asignación de ambas funciones están determinadas por una jerarquía universal que ordena las funciones semánticas según su centralidad respecto a la predicación. El "punto de interrupción" para la asignación de la función Objeto en inglés se establece después de la función semántica Beneficiario. Sin embargo, aparte de las funciones Meta, Receptor y Beneficiario, existen otros candidatos menos prototípicos que pueden funcionar como Objeto en esta lengua, ya que, como intentaré demostrar en este trabajo, la asignación de esta función es una cuestión de grado (cfr. Brdar y Brdar Szabó 1993).

\section{INTRODUCTION}

The theory of Functional Grammar (FG) is characterized as "a general theory concerning the grammatical organization of natural languages" (Dik, 1997: 2), ${ }^{1}$ where functional (or relational) notions are given priority over categorial notions. The theory recognizes functional relations at three different levels (Dik, 1997: 26).

\footnotetext{
1 The theory of FG is presented in Dik (1997), the second and revised edition of the first volume (originally published in 1989).
} 
a. Semantic functions (Agent, Goal, Recipient, Beneficiary, etc.) specify the roles played by the terms involved in the state of affairs (SoA) ${ }^{2}$ designated by the predication.

b. Syntactic functions (Subject and Object) specify the "perspective" from which an SoA is presented in a given linguistic expression.

c. Finally, pragmatic functions (Theme, Topic, Focus, etc.) are assigned in accordance with the "informational status" of the elements of the clause in their communicative context.

As pointed out by Siewierska (1991: 74), the FG approach to Subject and Object assignment is one of the most controversial aspects of the theory. In what follows I will focus on the issue of Object assignment, dealt with in a rather vague manner within the model.

In the first part of this paper, I will explain the FG theory of Subject/Object assignment in general terms, commenting on the FG conception of "perspective", and discussing the Semantic Function Hierarchy proposed by Dik (1997: 266) as the factor determining accessibility to Subject and Object. I will then try to clarify the FG interpretation of Objecthood in English, where the cut-off point for Object assignment is established after Beneficiary. In the second part, I will present some marginal possibilities for Object assignment in English, which find no direct explanation through the SFH hypothesis. The implications of the analysis for the FG model will be explored in $\S 3$.

\section{THE FG APPROACH TO SUBJECT/OBJECT ASSIGNMENT}

\subsection{Perspective in FG}

FG offers a very restrictive view of syntactic functions as compared to both traditional grammar and other current grammatical frameworks (cf. Siewierska, 1991: 73). The theory recognizes only two grammatical relations: Subject and Object, ${ }^{3}$ which are not morphosyntactic but "perspectival", since they define different vantage points over the SoA designated by the predication. The Subject is taken to determine the primary vantage point for presenting the SoAs, whereas the Object is interpreted as marking the secondary vantage point. These two perspectives are defined on the basis of the active/passive opposition in the case of the primary perspective (see (1)), and in terms of the so-called "dative-shift" opposition in the case of the secondary perspective (see (2)): ${ }^{4}$

(1) a. Jeff hit the child.

b. The child was hit by Jeff.

(2) a. Charles gave a rose to Anna.

b. Charles gave Anna a rose.

\footnotetext{
${ }^{2}$ An SoA is defined as "the conception of something that can be the case in some world" (Dik, 1997: 51).

${ }^{3}$ While semantic and pragmatic notions are regarded as universal functions, playing a role in the grammar of every language, syntactic notions are not considered to be universally relevant.

${ }^{4}$ The examples in (1) and (2) are taken from Siewierska (1991: 79).
} 
In (1a) the act of hitting is presented from the point of view of "Jeff", the Agent, in (1b) from the perspective of "the child", the Goal. In (2a) the secondary perspective is that of "a rose", the Goal, in (2b) that of the Recipient, "Anna".

The active/passive and dative-shift oppositions are used in FG not only to exemplify differences in perspective, but also to define Subject and Object assignment. The existence of a productive active/passive opposition and the occurrence of dative-shift constructions in a given language are necessary conditions for recognizing, respectively, Subject and Object assignment in that language. In other words, for languages which lack either or both of these oppositions no Subject or Object functions are posited. Thus, as pointed out by Siewierska (1991: 79), "syntactic functions both determine and are determined by perspective".

FG gives a semantic interpretation to the Subject and Object functions. As shown in (1) and (2), different assignments of S and O lead to different presentations of the SoA designated by the predication. ${ }^{5}$

As Siewierska (1991: 74) points out, "the key notion in the FG view of perspective is sameness of SoA". Differences in perspective obtain only between predications representing the same SoA. Thus, the FG narrow approach to perspective excludes from its domain of oppositions like the ones exemplified below: ${ }^{6}$

a. reciprocal predicates:

(3) a. Sam met Sandy at the station.

b. Cindy met Sam at the station.

c. Sam and Cindy/Cindy and Sam met at the station.

b. converse predicates:

(4) a. Jill sold the car to Bill.

b. Jack bought the car from Jill.

c. so-called ergative predicates:

(5) a. Fred rolled the ball down the hill.

b. The ball rolled down the hill

d. locative and instrumental alternations:

(6) a. Max loaded hay onto the wagon.

b. Max loaded the wagon with hay.

\subsection{The Semantic Function Hierarchy}

Subject and Object may be assigned to terms with different semantic functions. In FG the semantic functions correspond to what in other grammatical frameworks are called semantic or thematic roles, relations or cases (cf. Siewierska 1991: 9).

\footnotetext{
${ }^{5}$ It should be noted that although the label "syntactic" is used (mainly for traditional reasons), the Subject and Object functions are defined notionally in relation to the FG conception of perspective (cf. Siewierska, 1991: 74).

${ }^{6}$ The examples in (3), (4), (5) and (6) are taken from Siewierska (1991: 77-78).
} 
The syntactic functions Subject and Object may be assigned to terms with different semantic roles. ${ }^{7}$ The choice of what semantic roles can be specified as Subject and Object is governed by the Semantic Function Hierarchy (SFH) presented in (7) below.

$$
\text { Agent }>\text { Goal }>\text { Recipient }>\text { Beneficiary }>\text { Instrumental }>\text { Locative }>\text { Time }
$$

Subj

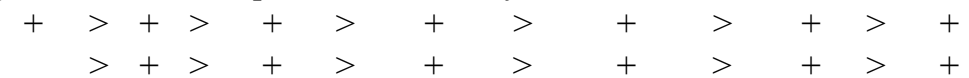

Obj

The SFH proposed by Dik as the factor determining accessibility to Subject/Object is conceived of as a language universal, with different "cut-off points" for different languages. ${ }^{8}$ In Dik's (1997: 266) terms, "the idea is that, as we proceed through the SFH from the more 'central' to the more 'peripheral' semantic functions, Subject and Object assignment become more and more 'difficult', and the resulting constructions become more and more 'marked'."

We have seen that a necessary condition for the recognition of distinctive Object assignment in a language is the existence of an opposition such as the one exemplified in (2) in $§ 2.1$. above. However, Dik (1997: 264) also admits the possibility of assigning Object to the Beneficiary in English, as shown in the pattern below:
a. John (AgSubj) bought the book (GoObj) for Peter (Ben).
b. John (AgSubj) bought Peter (BenObj) the book (Go).

In terms of FG analysis, the cut-off point for Object assignment is established after the Beneficiary. Just as Subject assignment is not restricted to Agents and Goals, so Object assignment is not restricted to Goals and Recipients.

The "syntactic" functions Subject and Object are sufficient to account for the relevant differences between linguistic expressions which represent the same predication. There is no syntactic function corresponding to "indirect object". FG assumes that the traditional notions of direct and indirect object can be subsumed under a single relation (cf. Perlmutter, 1981: 343). Indirect objects are reconstructed as either pure Recipients and Beneficiaries (as, for example, in John gave the book (GoObj) to Peter (Rec) / John bought the book (GoObj) for Peter (Ben)) or as Recipient-Objects and Beneficiary-Objects (as in John gave Peter (RecObj) the book (Go) / John (AgSubj) bought Peter (BenObj) the book (Go) $)^{9}$.

Dik (1997: 259) points out that the identity of SoAs is not a sufficient condition for recognizing the relevance of Object assignment in a language. The terms labelled "Objects" must have some "coding" and "behavioural" properties, in the sense of Keenan (1976: 324-325). Therefore, for Object assignment to be relevant in a language, some non-first argument must share a number of behavioural properties with the second argument of the active construction. ${ }^{10}$

\footnotetext{
${ }_{7}$ Dik (1997: 271) argues that, in certain cases, Subject and Object assignment may require reference to the notions of "first argument" (A1) and "second argument" (A2), which denote the conventional positions associated with a given predicate frame.

${ }^{8}$ The "cut-off point" is the end-point in the hierarchy below which Subject and Object assignment is not possible for a given language.

${ }^{9}$ Cf. Dik (1983: 20).

${ }^{10}$ These criteria also apply in the case of Subject assignment: identity of SoA, and coding and behavioural properties in common, this time with the first argument of the active construction (Dik, 1997: 260).
}

Odisea, $n^{\circ} 4,2003$ 
Although the author does not explicitly mention which the coding and behavioural properties for Object assignment are, I assume that the most relevant coding properties shared by objects in English are the following: occurrence in positions reserved for objects, i.e. second argument positions; absence of prepositional marking, ${ }^{11}$ and objective marking for pronominal objects (cf. Brdar and Brdar Szabó, 1993: 18). Finally, the most significant behavioural property of objects involves passivization: ${ }^{12}$ if a language has a regular opposition between active and passive constructions, Object assignment will entail Subject assignment in the corresponding passive voice sentence. ${ }^{13}$

There is therefore considerable overlap between the class of items identified as bearing the Object function in FG and the more familiar morpho-syntactically defined set of objects. As Siewierska (1991: 75) rightly points out, this partial identity makes it difficult to understand the FG position on syntactic functions.

\section{MARGINAL ACCESSIBILITY TO OBJECT ASSIGNMENT IN ENGLISH}

The three semantic functions eligible for Object assignment in English, where the cutoff point is established after the Beneficiary, are defined in (9) below: ${ }^{14}$

$$
\begin{aligned}
& \text { Goal (Go): the entity affected or effected by the operation of some } \\
& \text { controller } \\
& \text { (Agent/Positioner) or Force. } \\
& \text { Recipient (Rec): the entity into whose possession something is } \\
& \text { transferred. } \\
& \text { Beneficiary (Ben): the person or institution for whose benefit (sometimes } \\
& \text { against whose interest) the SoA is effected. }
\end{aligned}
$$

The Goal is the exclusive domain of the second argument, while the Recipient may be borne either by the second argument or the third (cf. Siewierska, 1991: 70). It should be noted that, in the FG framework, arguments are terms whose presence is necessary for the definition of the SoA designated by the nuclear predication. The Beneficiary, however, is a satellite, i.e. an additional participant in the SoA defined in the predication.

\footnotetext{
${ }_{11}$ Object assignment entails the "neutralization" of any overt morphological expression of the underlying semantic function. In Spanish, for instance, Object assignment is not relevant because the Recipient always receives the same marking (the preposition "a"), regardless of its position in the sentence: John le dio el libro a Mary ("John gave the book to Mary") / John le dio a Mary el libro ("John gave Mary the book").

12 There are other constructions that also point to the importance of (direct) objects in the grammar of English. Van Valin (2001: 65) mentions dative-shift, the locative and instrument alternations, and reflexivization (direct objects can be the antecedents of reflexive pronouns) among the most significant object properties in simple sentences.

${ }^{13}$ Rice's (1987: 422) proposal is interesting in that she argues that English clauses passivize according to "their adherence to a transitive prototype characterizable in conceptual terms." The author, who sustains that transitivity is not exclusively derivable from the morphological or predicate-argument properties of the clause, claims that there is no clear cut-off point demarcating passivizable and non-passivizable clauses, "because the 'transitivity threshold' that correlates with passive changes under varying lexical and clausal conditions." (Rice, 1987: 433).

${ }^{14}$ Cf. Dik (1997: 118, 121, 229).
} 
Having outlined the basic tenets of Object assignment in FG, I can now proceed to examine some examples illustrating marginal accessibility to Objecthood in English. I will present three types of non-Goal-NPs, which are considered as (direct) Objects in many traditionally oriented grammars: instrumental objects, locative objects and cognate objects.

\subsection{Locative Objects}

There is a great number of noun phrases in English denoting places that appear in positions reserved for Objects. As illustrated in (10) below, in these cases there seems to be a more or less regular opposition between prepositional phrases containing a locative noun as the head, and a prepositionless term in which the semantic function is neutralized as to marking (cf. Quirk et al., 1985: 749). ${ }^{15}$
a. We walked the streets.
We walked through the streets.
b. She swam the river.
She swam across the river.
c. He passed a cyclist.
He passed by a cyclist.
$\mathrm{d}$. The horse jumped the fence.
The horse jumped over the fence.

The status of these locative NP as Objects is clear from their ability to be passivized (e.g. The fence was jumped by the horse). ${ }^{16}$ However, as Quirk et al. (1985: 685) point out, in many cases there is a difference in meaning between the two constructions. Compare the examples in (11) in this regard:

a. Let's swim across the river.

b. She was the first woman to swim the Channel.

The construction with preposition (11a) draws attention to the process, whereas the direct object construction (11b) has "perfective" meaning, indicating that the objective is achieved.

\subsection{Instrumental Objects}

Instrumental objects may be defined as prepositionless NPs designing the entity which an agent uses to perform an action or instigate a process (cf. Quirk et al., 1985: 743):
a. We employ a computer for our calculations.
b. She is playing the piano.
c. He nodded his head.

As illustrated by Brdar and Brdar Szabó (1993: 20), with some motion verbs there is an opposition between "prepositionally marked" and "prepositionless instrument terms":

\footnotetext{
${ }^{15}$ See Quirk et al. (1985: 685) for further examples.

${ }^{16}$ However, as pointed out by Brdar and Brdar Szabó (1993: 21), the.process is not fully productive (e.g. The child crawled across the floor / *The child crawled the floor).
} 
As in the examples in $\S 3.1$ and $\$ 3.2$ above, we can argue that the italicized elements in (12) and (13) are Objects since they meet the coding and behavioural requirements listed in \$2.2. Dik (1997: 124), however, does not treat Instrument as a nuclear argument, since "it can normally be left out without affecting the grammaticality or the semantics of the remaining predication." The author (1997: 123), who emphasizes the necessity of distinguishing between the lexical meaning of a term and its semantic function, argues that "semantic functions not only concern the content of the predication, but also the form into which this content has been moulded." Consequently, in a sentence like John used the money to bribe the policeman, the money is not assigned the Instrument function, although it is clearly the entity used by the Agent (John) to perform the action denoted by the verb.

\subsection{Cognate Objects}

Finally, let us consider a type of object whose semantic function is to repeat, wholly or partially, the meaning of the verb (cf. Quirk et al., 1985: 750).
a. They fought a clean fight.
b. He died a miserable death.
c. She lived a good life.
d. He breathed his last breath.

In this type of object (semantically and/or morphologically related to the verb) the noun head is often premodified by an ajective. As pointed out by Quirk et al. (1985: 750), the verb and the cognate object are then equivalent to the verb and a corresponding adverbial:
a. They fought a clean fight.
They fought cleanly.
b. He died a miserable death.
He died miserably.

I concur with Brdar and Brdar Szabó (1993: 24) that cognate objects are "instances of objectivization of the semantic function Manner," since they specify the manner in which the activity denoted by the verb is performed. It is noticeable, however, that there is no Manner in Dik's SFH. We can then conclude that, as suggested by Siewierska (1991: 237238), the range of semantic functions covered by Dik's SFH does not exhaust all the syntactic function assignment possibilities.

\section{CONCLUDING REMARKS}

The examples that I have shown so far may call for a revision of the FG approach to Object assignment in English. Although the oppositions exemplified in 3.1, 3.2 and 3.3 
(e.g. The horse jumped the fence vs The horse jumped over the fence or Stop twiddling your pencil vs Stop twiddling with your pencil) do not come under Dik's narrow conception of perspective, I contend that these alternative renderings could be considered in FG as reflections of a wider kind of perspective. Therefore, if the above object-like items can indeed be taken as some sort of objects, it seems obvious that cut-off points for Object assignment are not easy to establish. The assignment of the Object function does not seem to be restricted to the three first functions on Dik's semantic hierarchy, i.e. Goal, Recipient and Beneficiary.

As suggested by Brdar and Brdar Szabó (1993: 24), who try to incorporate the prototype approach into FG, the productivity of Object assignment is a matter of degree, i.e., there are some semantic functions which, being out of bounds for Object assignment, are marginally accessible to the Object function.

Along these lines, Mackenzie (1981: 315) questions the validity of the notion "cutoff point" as defined by Dik with regard to Subject assignment English. According to Mackenzie, there are examples that show that, while many Recipients cannot be assigned Subject function (eg *I (Rec) was muttered the secret), certain Instruments and Locations can (eg Twenty dollars (Instr) will buy you a square meal / The tank (Loc) has sprung a leak). ${ }^{17}$

In consonance with Brdar and Brdar Szabó, Goossens (1994: 71 ff), who tries to integrate the notion of transitivity as conceived of in Cognitive Grammar within the FG framework, speaks of an "extended" Goal prototype. Goossens' proposal is to add the "feature" Affected (and more rarely the feature Effected) to non-first arguments other than Goals, which are thus assimilated to the transitive prototype. In the author's (1994: 75) words, "construing an argument or satellite as Affected implies that the state of affairs is (often metaphorically) conceived of as involving a transfer of energy from the first argument to some other asymmetrical entity." 18 The addition of the feature Affected to the object-like NPs shown in $\$ 3$ would thus make them eligible for Object assignment.

The phenomenon of Object assignment in FG undoubtedly deserves a more detailed study in a cross-linguistic perspective. I hope, however, that the data I have presented here may help to cast a new light on one of the most confusing areas in FG.

\section{REFERENCES}

Brdar, M. and R. Brdar Szabó. 1993. "FG and prototype theory: a case study from English, German, Croatian and Hungarian". Working Papers in Functional Grammar 51.

Dik, S.C. 1983. "Basic principles of functional grammar". Advances in Functional Grammar. Publications in Language series. Ed. S.C. Dik. Dordrecht: Foris Publication. 3-28.

1997. The Theory of Functional Grammar. Part 1. The Structure of the Clause. $2^{\text {nd }}$ rev. ed. Berlin: Mouton de Gruyter.

\footnotetext{
${ }^{17}$ Mackenzie's claims clearly contradict Dik's view on the subject (cf. §3).

${ }^{18}$ Goossens' proposal is clearly in accordance with Rice's (see note 13).
}

Odisea, $n^{\circ} 4,2003$ 
Goossens, L. 1994. "Transitivity and the treatment of (non-)prototypicality in FG". Function and Expression in Functional Grammar. Functional Grammar Series 16. Berlin: Mouton de Gruyter.

Hoekstra, T., H. van Der Hulst and M. Moorgat, eds. 1981. Perspectives on Functional Grammar. Dordrecht: Foris

KeEnan, E.L. 1976. "Towards a universal definition of subject". Subject and Topic. Ed. C.N. Li. New York and London: Academic Press. 303-333.

MackenZie, L. 1981. "Functions and cases". Eds. T. Hoekstra, et al. 299-318.

Perlmutter, D.M. 1981. "Functional Grammar and Relational Grammar: points of convergence and divergence". Eds. T. Hoekstra, et al. 319-352.

RicE, S. 1987. "Towards a Transitive Prototype: Evidence from Some Atypical English Passives". Proceedings of the $13^{\text {th }}$ Meeting of the Berkeley Linguistic Society. 13. 422-434.

Quirk, R., S. Greenbaum, G. LeEch and J. Svartvik. 1985. A Comprehensive Grammar of the English Language. London: Longman.

SiewiersKa, A. 1991. Functional Grammar. London / New York: Routledge.

Van Valin, R. 2001. An Introduction to Syntax. Cambridge: Cambridge University Press. 